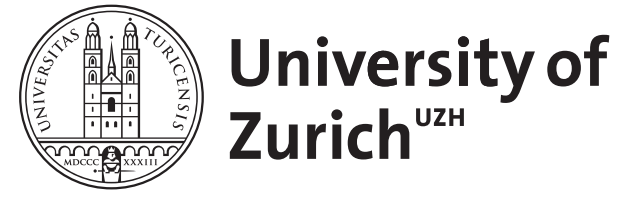
Archive

University of Zurich

University Library

Strickhofstrasse 39

CH-8057 Zurich

www.zora.uzh.ch

Year: 2010

\title{
Reversal of canities
}

Navarini, Alexander A ; Trüeb, Ralph M

DOI: https://doi.org/10.1001/archdermatol.2009.337

Posted at the Zurich Open Repository and Archive, University of Zurich ZORA URL: https://doi.org/10.5167/uzh-43080

Journal Article

Originally published at:

Navarini, Alexander A; Trüeb, Ralph M (2010). Reversal of canities. Archives of Dermatology, 146(1):103104.

DOI: https://doi.org/10.1001/archdermatol.2009.337 

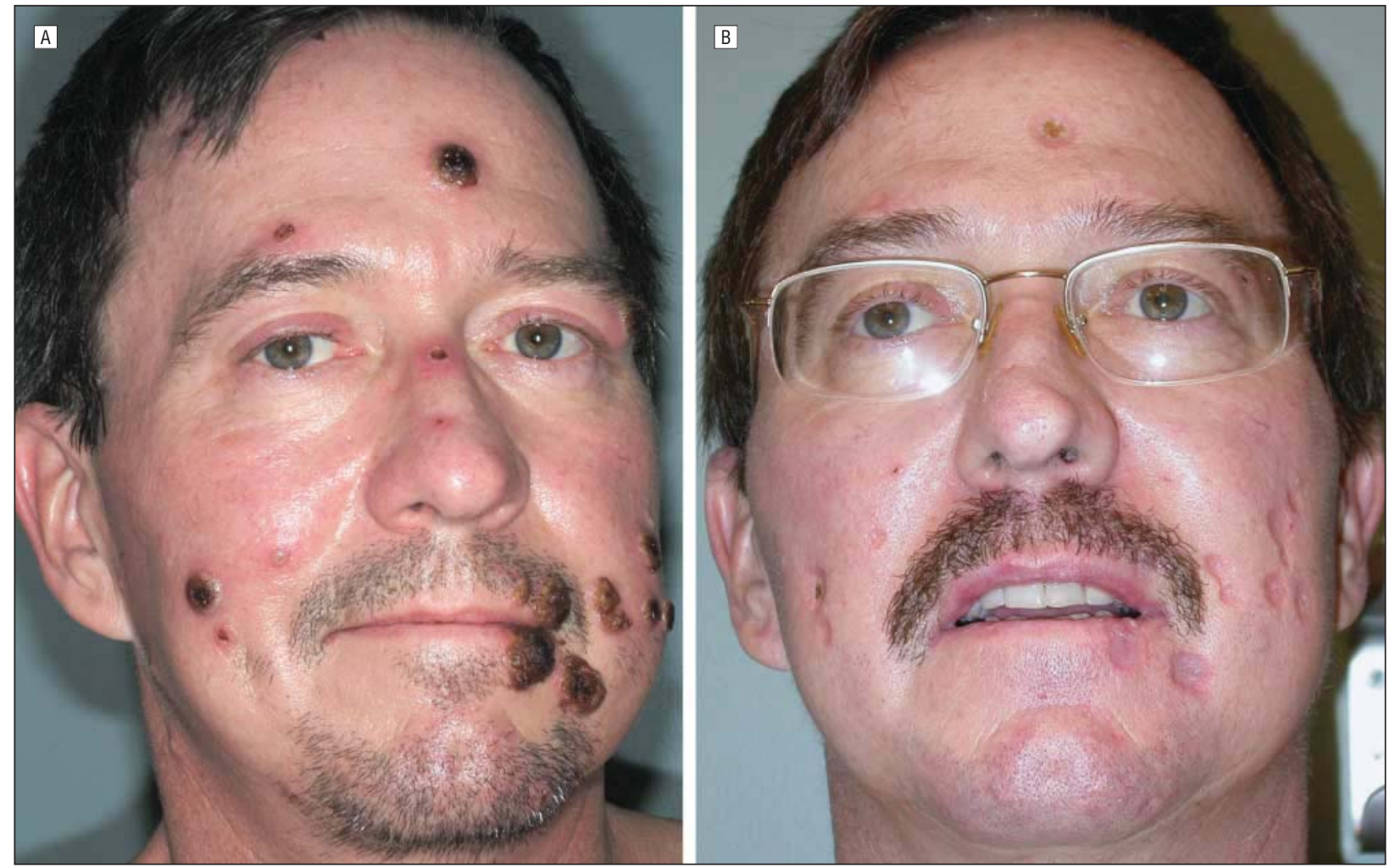

Figure. Clinical appearance of malignant pyoderma. A, Patient with extensive papulopustules and skin ulcers prior to treatment. B, Patient with cribriform scars 6 months after treatment.

young adults. It is unclear whether MP is distinct from PG. ${ }^{2}$ The reported MP cases have similar clinical features, such as facial and preauricular ulceration, while, in contrast to PG, they lack undermining or surrounding erythema. Defects in cell-mediated and humoral immunity as well as lymphocyte, neutrophil, and monocyte function have been reported, but none of these findings have been demonstrated consistently. $^{3}$

Malignant pyoderma remains a therapeutic challenge. ${ }^{3,4}$ Although high-dose systemic corticosteroids and dapsone may induce clinical remission in many patients, refractory cases have been described. ${ }^{5}$ Treatments with systemic corticosteroids, cyclosporine, dapsone, azathioprine, tacrolimus (FK506), chlorambucil, mycophenolate mofetil, methotrexate, and infliximab have all been reported to improve the skin manifestations to various degrees. ${ }^{2,4,5}$ In the present case, rapid disease progression, significant tissue destruction, and refractoriness to steroids prompted increased immunosuppression with a combination of agents including tacrolimus, dapsone, and corticosteroids. The clinical response was excellent. In conclusion, it appears that this combination is effective and safe in patients with MP, and it can be considered first-line treatment in aggressive disease refractory to corticosteroids.

Ana M. Ciurea, MD Joan Guitart, $M D$ Joaquin Brieva, MD
Correspondence: Dr Ciurea, Department of Dermatology, University of Texas, M. D. Anderson Cancer Center, 1400 Pressler St, Unit 1452, Houston, TX 77030 (mciurea@mdanderson.org).

Financial Disclosure: None reported

1. Perry HO, Winkelmann RK, Muller SA, Kierland RR. Malignant pyoderma. Arch Dermatol. 1968;98(6):561-576.

2. Gibson LE, Daoud MS, Muller SA, Perry HO. Malignant pyodermas revisited. Mayo Clin Proc. 1998;73(4):390.

3. Crowson AN, Mihm MC Jr, Magro C. Pyoderma gangrenosum: a review. J Cutan Pathol. 2003;30(2):97-107.

4. Bennett ML, Jackson JM, Jorizzo JL, Fleischer AB Jr, White WL, Callen JP. Pyoderma gangrenosum: a comparison of typical and atypical forms with an emphasis on time to remission: case review of 86 patients from 2 institutions. Medicine (Baltimore). 2000;79(1):37-46

5. Weichert G, Sauder DN. Efficacy of tacrolimus (FK 506) in idiopathic treatmentresistant pyoderma gangrenosum. J Am Acad Dermatol. 1998;39(4, pt 1): 648-650.

\section{Reversal of Canities}

Report of a Case. A 67-year-old, otherwise healthy man presented with spontaneous repigmentation of his gray hair (Figure).

Comment. The reports on this phenomenon are scant in the literature ${ }^{1-4}$ though it may not be as rare as assumed. In fact, it is not too uncommon to see spontaneous repigmentation along the same individual hair shaft in early canities (loss of hair pigment resulting in graying of the hair). Moreover, melanocytes taken from white hair follicles can be induced to pigment in vitro. ${ }^{5}$ The most dramatic cases of return of normal hair color from white 


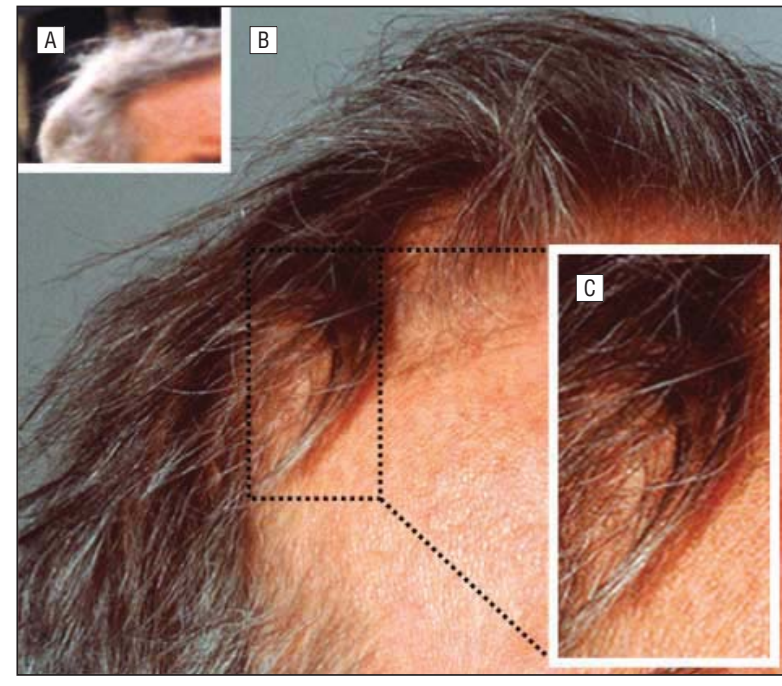

Figure. Clinical images of spontaneous hair repigmentation. A, Gray scalp hair of patient before onset of spontaneous repigmentation. B, Universal reversal of canities. C, Close-up view of hair strands: while the distal hair shafts are white, the proximal hair shafts show dark pigmentation.

are probably examples of pigmented hair re-growth following alopecia areata or the Marie Antoinette syndrome. ${ }^{6}$ Repigmentation of hair observed in Addison disease has been attributed to a mechanism similar to that seen in alopecia areata, in view of the known association between these 2 presumably autoimmune diseases. On the other hand, it may also be explained through the effect of elevated levels of melanocyte-stimulating hormone, which applies to pigmentation of skin and hair in Nelson syndrome and ectopic adrenocorticotropic hormone syndrome as well. Since the stimulation of pigment formation may also affect the hair, a conspicuous darkening of the hair should suggest the possibility of these disorders. In our patient, however, careful evaluation for underlying endocrinologic disorders or neoplastic disease did not reveal any abnormalities.

\section{Alexander A. Navarini, $\mathrm{MD}, \mathrm{PhD}$ Ralph M. Trüeb, MD}

Correspondence: Dr Trüeb, Department of Dermatology, University Hospital of Zurich, Gloriastrasse 31, 8091 Zurich, Switzerland (ralph.trueeb@usz.ch).

Financial Disclosure: None reported.

Funding/Support: This study was supported by the Department of Dermatology, University Hospital of Zurich.

1. VERITAS. White hair turned black. http://query.nytimes.com/mem/archive-free /pdf?_r=1\&res=9506E3DF123FE633A25756C0A96E9C946296D6CF. Accessed July 23, 2009

2. Comaish S. White scalp hairs turning black-an unusual reversal of the ageing process. Br J Dermatol. 1972;86(5):513-514

3. Tobin DJ, Cargnello JA. Partial reversal of canities in a 22-year-old normal Chinese male. Arch Dermatol. 1993;129(6):789-791.

4. Pattier P. Spontaneous repigmentation of white hair [in French]. Ann Dermatol Venereol. 2001;128(10, pt 1):1082-1083.

5. Tobin DJ, Paus R. Graying: gerontobiology of the hair follicle pigmentary unit. Exp Gerontol. 2001:36(1):29-54.

6. Navarini AA, Nobbe S, Trueb RM. Marie Antoinette syndrome. Arch Dermatol. 2009;145(6):656. 